\title{
STUDIES ON THE RELATIONSHIP BETWEEN OXYGEN CONSUMPTION AND NITROGEN METABOLISM. \\ I. IN PERNICIOUS ANEMIA
}

\author{
By C. W. BALDRIDGE AND ADELAIDE BARER
}

(From the Department of Internal Medicine, University Hospitals, State University of Iowa, Iowa City)

(Received for publication February 25, 1931)

In this communication we are reporting the first of a series of metabolic studies in certain diseases in which there is an altered rate of oxygen consumption without a recognized disturbance in thyroid function. We wish particularly to stress a correlation between oxygen consumption and protein metabolism. Data obtained by a study of six patients with pernicious anemia are presented and discussed.

Many metabolic studies have been made in pernicious anemia. Some of the factors which were most disturbing in the earlier work are now controllable. We refer to the fact that remissions in the disease can be brought about rapidly and consistently by therapeutic measures and such remissions can be recognized early by means of the reticulocyte crisis. Our primary concern has been to determine and to explain, if possible, the variations in oxygen consumption during relapses, reticulocyte crises, and regenerative periods in pernicious anemia.

\section{REVIEW OF LITERATURE}

Observations on the oxygen consumption in patients with pernicious anemia are quite numerous in the literature. The earlier reports were, for the most part, only single basal metabolic rates which were normal or moderately increased. Such observations were made by Meyer and DuBois (1), Tompkins, Brittingham and Drinker (2), Grafe (3), and Boothby and Sandiford (4). Meyer and DuBois suggested that the oxygen consumption was increased in severe anemia. Later some investigators made repeated examinations on the same patient, and learned that the oxygen consumption usually decreased as the blood count increased. Among these observers were Becker (5), Richards and Strauss (6), Alt (7), and Grassheim (8).

Previous to 1926 , studies on nitrogen metabolism in pernicious anemia 
gave conflicting results. Some patients would show nitrogen retention and others nitrogen loss, and occasionally a shift from negative to positive nitrogen balance would occur in a patient while under observation. It was demonstrated that the nitrogen balance was not necessarily dependent upon the hemoglobin content of the blood or the protein intake. Studies were made before and after splenectomy and considerable effort was made to determine the proportion of nitrogen eliminated as urea and uric acid, but in many instances it is not possible now to tell whether the disease was in a regenerating or a relapsing phase when these observations were made. Gibson and Howard (9) obtained nitrogen retention by giving a diet (10) containing fifty grams of liver per diem. Alt recently showed that the

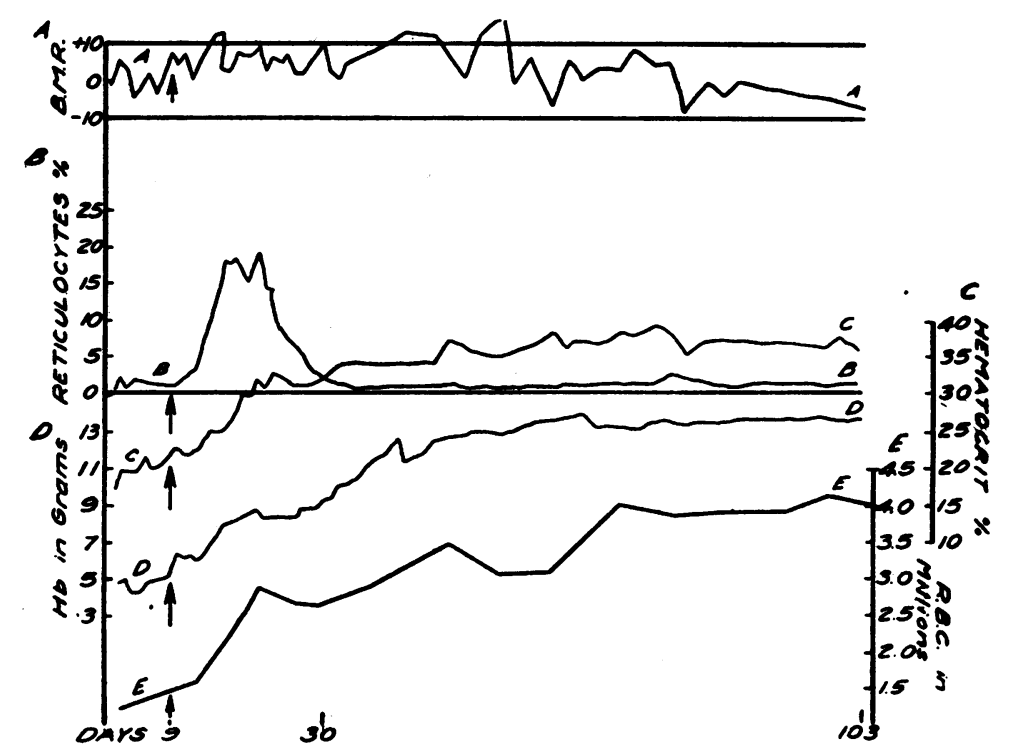

Chart 1. Case 1

Case 1, L. M., female, aged 46 years. The total period of observation was 103 days. Determinations were made daily for 34 days, once during the sixth week and tri-weekly thereafter except that the basal metabolic rate was not done on the fifth day and no observations were made between the eighty-sixth and ninety-eighth days. Erythrocyte counts were made frequently. The treatment consisted of $4 \mathrm{cc}$. of dilute hydrochloric acid with each meal and three vials of Lilly's liver extract daily, beginning after a control period of 9 days. General hospital diet was given for the first 36 days and high caloric general diet for the succeeding 67 days. The body weight increased from $53.0 \mathrm{kgm}$. to $63.5 \mathrm{kgm}$. During the period 57 determinations of the basal metabolic rate were made with duplicate gas analyses. 
nitrogen balance shifts from a negative to a positive phase soon after treatment with liver extract is begun. However, one might rightly object to Alt's assumption that the stools contain one gram of nitrogen per diem. (See data on Case 6.) No doubt the earlier and very careful metabolic studies yielded variable results because the observers lacked the present methods for producing and recognizing remissions.

The water balance in pernicious anemia has been carefully studied by Meulengracht and his associates (11), who found that water is of ten retained during relapses and excreted normally during remissions. It is their contention that the water retention is not due to low hemoglobin content of the blood nor renal insufficiency but may be dependent upon the lowered colloid osmotic pressure of the plasma. Alt found a decrease in urinary

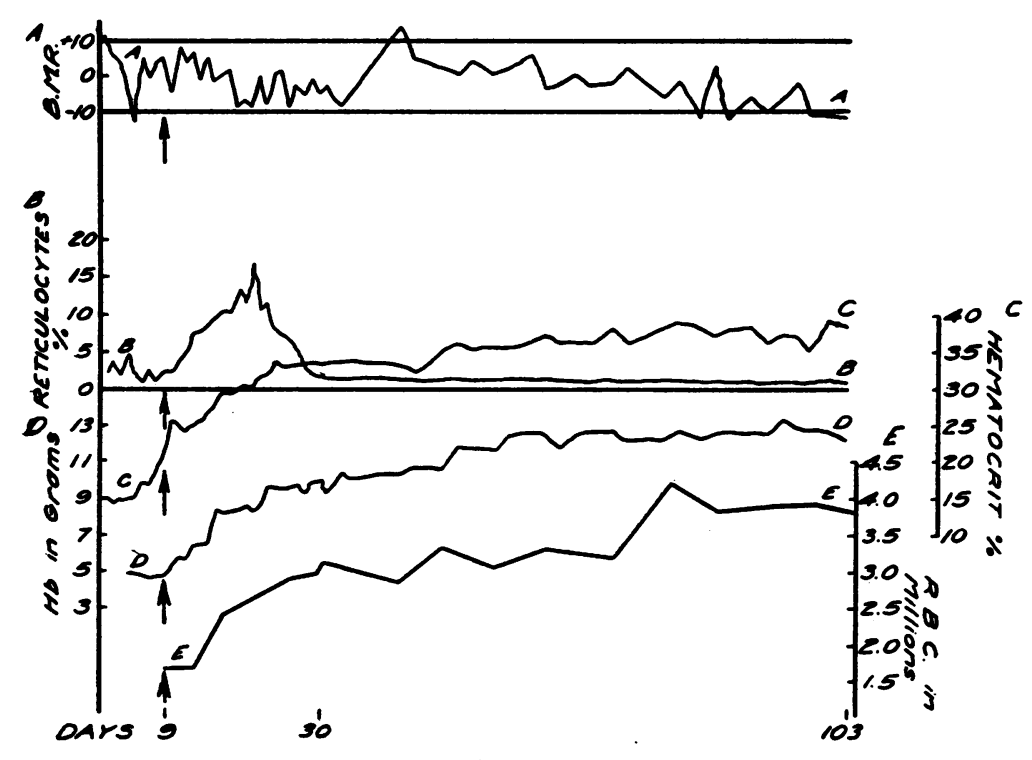

Chart 2. Case 2

Case 2, L. D., female, aged 50 years. The total period of observation was 103 days. Determinations were made daily for 34 days, once during the sixth week and tri-weekly thereafter. Erythrocyte counts were made frequently but not daily. Treatment consisted of $4 \mathrm{cc}$. of dilute hydrochloric acid with each meal and of $45 \mathrm{cc}$. of Armour's liver extract daily after a control period of 9 days. General hospital diet was given for the first 36 days and a high caloric general diet for the succeeding 67 days. The body weight increased from $44.2 \mathrm{kgm}$. to $56.2 \mathrm{kgm}$. During the period 61 determinations of the basal metabolic rate were made. 
volume during the reticulocyte crisis with an increased output later in the regenerative period. An accurate water balance is very difficult to obtain because the factors which ordinarily affect the imperceptible water loss are hard to control over long periods. The amount of imperceptible water loss is further disturbed if there be a changing basal oxygen consumption.

\section{METHODS AND RESULTS}

Our first consideration was to determine as accurately as possible the daily variation in oxygen consumption before, during and after the reticulocyte crises of induced remissions in pernicious anemia.

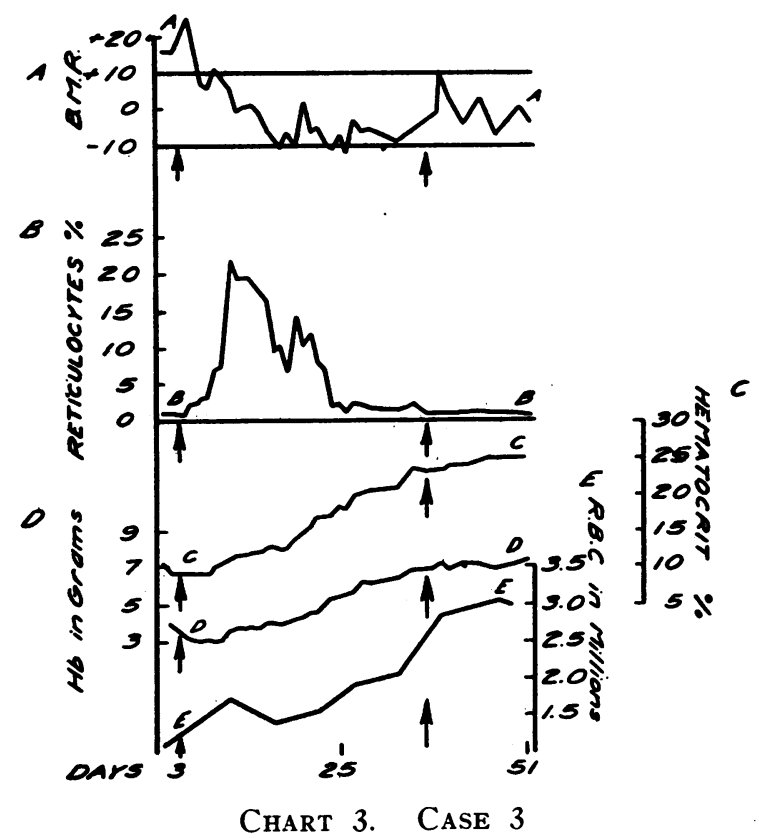

Case 3 , M. M., female, aged 45 years. Determinations were made daily for the first 28 days and tri-weekly thereafter except that the basal metabolic rate "was not done on the ninth day and erythrocyte counts were done periodically. The total period of observation was 50 days. Treatment consisted of $2 \mathrm{cc}$. of dilute hydrochloric acid with each meal and 1.5 grain of luminal daily for the first 34 days. The patient also received $45 \mathrm{cc}$. of Armour's liver extract daily after a control period of three days. On the thirty-sixth day the dose of liver extract was doubled. The diet varied considerably during the control period because of nausea and some vomiting. The body weight increased from $38.8 \mathrm{kgm}$. to $43.0 \mathrm{kgm}$. A total of 37 determinations of the basal metabolic rate was made. 
For this purpose six cases of typical and severe pernicious anemia were selected. In one patient the nitrogen balance was also determined because this seemed to be of great importance in explaining the variations in oxygen consumption.

The subjective and objective features upon which the diagnoses were based can be expressed most readily by means of the ten diagnostic points described by Rohner (12): (1) Previous remissions, (2) paresthesias, (3) glossitis, (4) subacute combined sclerosis, (5) color index greater than unity, (6) erythrocytes below 2.5 million, (7) leukopenia, (8) macrocytosis, (9) achlorhydria, (10) positive Van den Bergh.

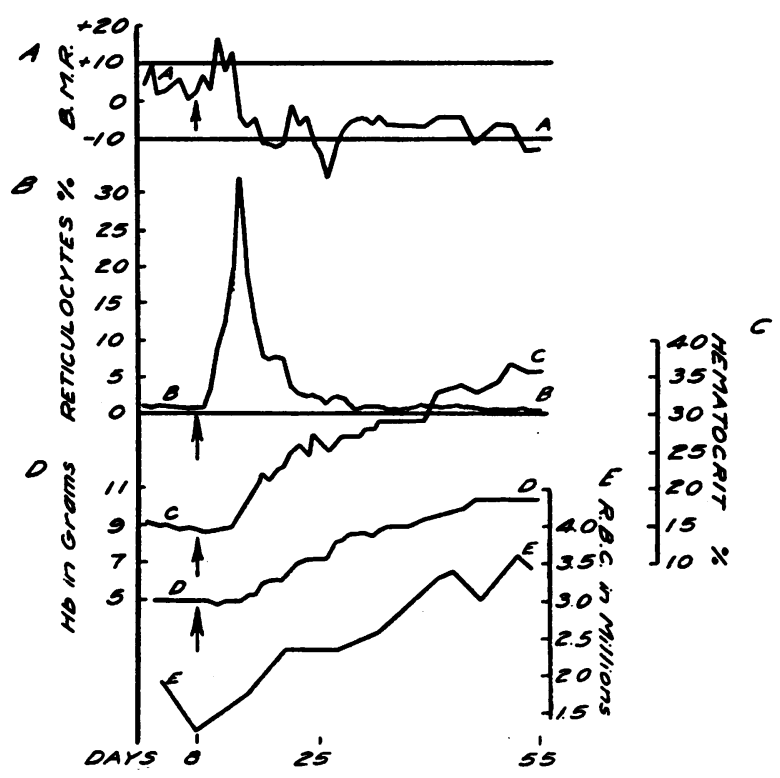

Chart 4. Case 4

Case 4, L. L.; female, aged 69 years. Determinations were made daily for 33 days and tri-weekly. thereafter except that the basal metabolic rate was not done on the fifth day and erythrocytes were enumerated 12 times during the period. The total period of observation was 55 days. Treatment consisted of $2 \mathrm{cc}$. of dilute hydrochloric acid with each meal, three grains of luminal daily from the twelfth day to the end of the period, and 6 vials of Lilly's liver extract daily after a control period of 8 days. General hospital diet was given. The weight increased from $50.7 \mathrm{kgm}$. to $53.3 \mathrm{kgm}$. Basal metabolic rate determinations were made on 41 occasions. 
In Cases 1, 2, 5, and 6 all of the diagnostic points were present. In Case 3 there had been no previous remissions and there was no evidence of subacute combined sclerosis. In Case 4 paresthesia and subacute combined sclerosis were absent.

The following determinations were made on each patient:

1. The basal metabolic rate by Tissot spirometer and Haldane gas analysis (average of two analyses for each reading).

2. Hemoglobin by the Newcomer method (19).

3. Hematocrit by the Van Allen method (20).

4. Reticulocyte counts (brilliant cresyl blue, 500 cells counted).

5. Erythrocyte counts.

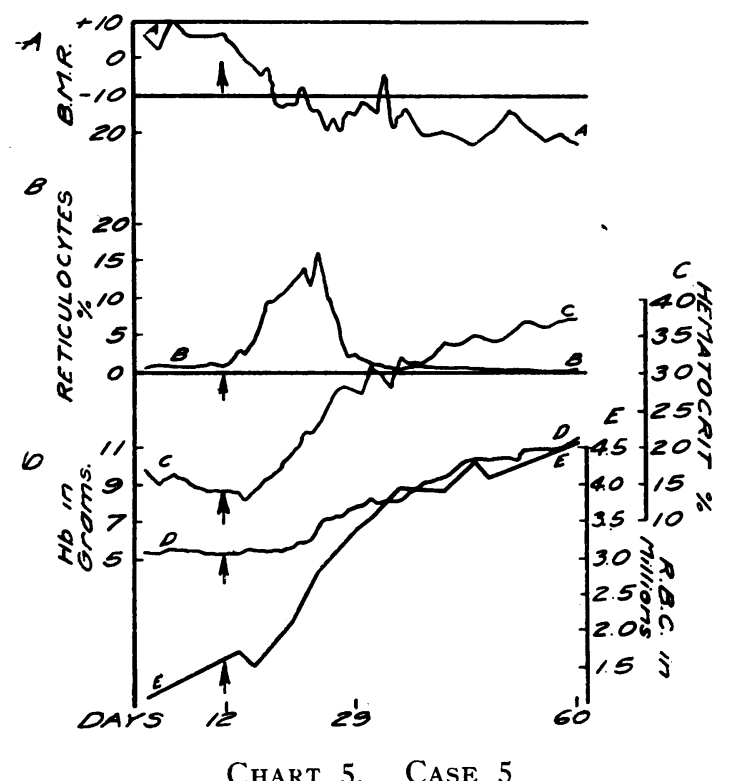

Case 5, C. S., male, aged 70 years. Observations were made on alternate days during a control period of 12 days, then daily for 25 days and tri-weekly thereafter except that the basal metabolic rate was not done on the thirteenth day. Only 13 erythrocyte counts were made during the 60-day period of observation. Treatment consisted of $3 \mathrm{cc}$. of dilute hydrochloric acid with each meal and 6 vials of Lilly's liver extract daily after a control period of 12 days. General hospital diet was given. The body weight increased from $61.6 \mathrm{kgm}$. to $63.3 \mathrm{kgm}$. Forty basal metabolic rate determinations were made. 


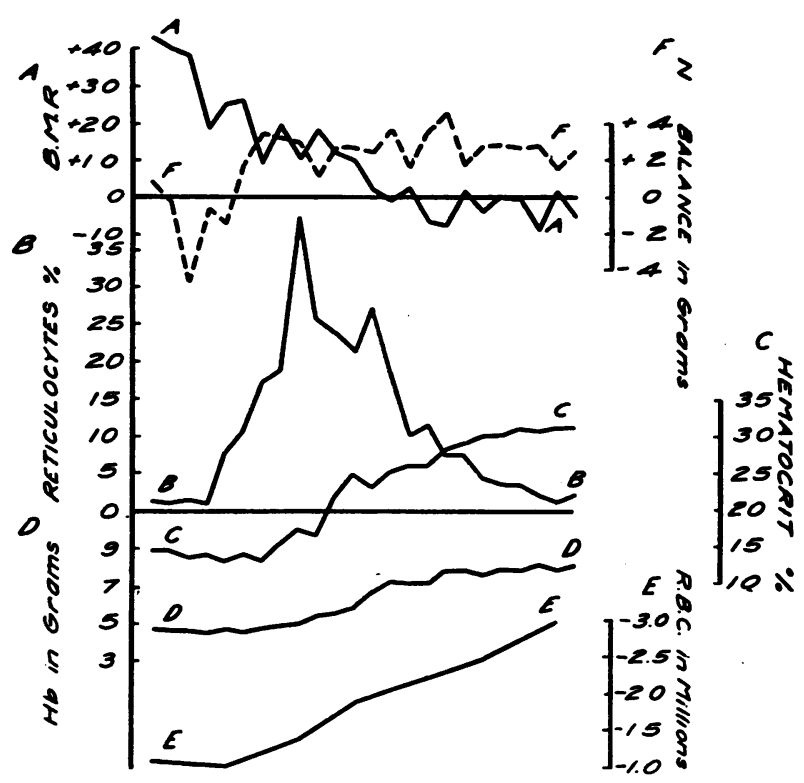

Chart 6. Case 6

Case 6, J. L., female, aged 46 years. All observations except erythrocyte counts were made daily for 24 days, which was the total period of study. In addition to the above mentioned determinations, water balance, nitrogen balance and nitrogen partition were done. Treatment consisted of $4 \mathrm{cc}$. of dilute hydrochloric acid with each meal and 6 vials of Lilly's liver extract daily, beginning after a control period of three days. The diet was weighed and refused portions were weighed after each meal. The body weight increased from $59 \mathrm{kgm}$. to $60.3 \mathrm{kgm}$.

\section{DISCUSSION}

Observation of the charts on the cases in this series will show that in all save one (Case 1 ) there was a definite and gradual decrease in the basal metabolic rate very soon after liver extract was begun. This decrease in oxygen consumption was most marked and uniform in the last three patients in whom the dose of liver extract was double that used in the first three cases. We will first consider the ordinary factors which may disturb the basal metabolic rate.

The body temperature is usually elevated during a severe relapse in pernicious anemia and is practically normal during a remission. As can be seen from the tabulations (Table 1) the fall in temperature 
TABLE 1

Temperature, pulse, respirations, respiratory quotient, and caloric requirements of the patients studied expressed in averages for the various periods

\begin{tabular}{|c|c|c|c|c|c|c|c|c|c|c|}
\hline & مि & 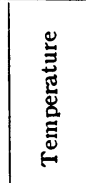 & 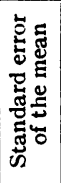 & 兽 & 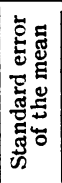 & 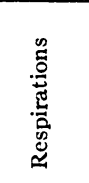 & 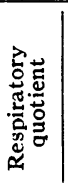 & 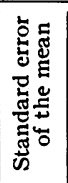 & 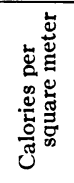 & 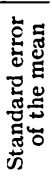 \\
\hline Case & & ${ }^{\circ} F$ & & $\begin{array}{c}\text { per } \\
\text { minute }\end{array}$ & & $\begin{array}{c}\text { per } \\
\text { minute }\end{array}$ & & & $\begin{array}{l}\text { per } \\
\text { hour }\end{array}$ & \\
\hline Control $\mathrm{p}$ & 9 & 98.8 & .11 & 84.5 & 1.2 & 19.9 & .723 & .006 & 36.3 & .4 \\
\hline Reticulocy & 20 & 98.5 & .08 & 83.1 & 0.8 & 20.0 & .730 & .004 & 38.1 & .2 \\
\hline Regeneratic & 74 & 98.2 & .04 & 85.1 & 0.7 & 20.0 & .740 & .005 & 37.2 & .1 \\
\hline $\begin{array}{r}\text { Case } \\
\text { Control p }\end{array}$ & 9 & 98.5 & .18 & 84.4 & 1.2 & 19.8 & .785 & .010 & 36.0 & .5 \\
\hline Reticulocy & 19 & 98.1 & .08 & 78.1 & 1.0 & 19.5 & .812 & .006 & 34.4 & .3 \\
\hline Regeneratio & 75 & 97.7 & .05 & 81.5 & 0.5 & 19.6 & .810 & .005 & 34.1 & .3 \\
\hline $\begin{array}{r}\mathrm{C} \\
\text { Cont }\end{array}$ & 3 & 100.0 & .19 & 96.4 & 3.0 & 21.1 & .732 & .005 & 41.9 & .3 \\
\hline Ret & 20 & 99.4 & .10 & 92.2 & 1.2 & 20.4 & .782 & .007 & 35.7 & .5 \\
\hline Regeneration & 29 & 98.7 & .04 & 80.6 & 0.7 & 19.6 & .843 & .008 & 34.7 & .4 \\
\hline & & & & & & & & & & \\
\hline Cont & 8 & 99.7 & .11 & 86.8 & 2.3 & 20.6 & .773 & .009 & 34.4 & .3 \\
\hline Reticuloc & 16 & 99.4 & .10 & 86.0 & 1.5 & 20.0 & .758 & .008 & 32.2 & .5 \\
\hline Regeneratio & 31 & 99.0 & .06 & 72.5 & 0.8 & 19.3 & .758 & .007 & 30.0 & .3 \\
\hline C & 12 & 98.5 & .09 & 67. & 0.9 & 18.5 & .784 & .006 & 37.7 & .3 \\
\hline Retic & 17 & 97.9 & .10 & 61.1 & 0.7 & 18.0 & .826 & .009 & 31.8 & .4 \\
\hline Regeneratio & 31 & 97.8 & .07 & 64.0 & 0.7 & 19.0 & .846 & .012 & 29.1 & .4 \\
\hline & & & & & & & & & & \\
\hline & 3 & 100.8 & .15 & 100.0 & 2.4 & 20.5 & .809 & .008 & 50.9 & .4 \\
\hline Reticuloc & 16 & 99.2 & .11 & 85.7 & 1.3 & 20.3 & .790 & .008 & 39.1 & .7 \\
\hline Regeneration period.. & 5 & 98.9 & .14 & 75.1 & 0.8 & 20.0 & .766 & .005 & 35.0 & .5 \\
\hline
\end{tabular}

Figures for temperature, pulse rate, and respiratory rate represent the average of three determinations per diem for the number of days indicated. Determinations were made at 8 A.M., 4 P.M., and 8 P.M. The respiratory quotient and calories per square meter per hour represent the average of two gas analyses for each determination during the period. Standard error of the mean $=\sqrt{\frac{\Sigma\left(d^{2}\right)}{n(n-1)}}$. 
was rather insignificant in most instances and certainly did not parallel the decrease in oxygen consumption. In addition, the temperature was usually most elevated in the afternoon, so that, although a morbid process which produced fever may have been present, the actual thermic disturbance was very slight or absent at the time of the test. While we can not exclude fever as a factor in increasing the basal metabolic rate at the beginning of the test periods, we can say that change in temperature was a factor of very minor or no importance in bringing about the decrease in oxygen consumption in which we are interested.

The pulse rate decreased slightly during the reticulocyte crises in some patients, but most of the decrease occurred later in the period of regeneration. The work of the heart in these patients can not be determined from the pulse rate alone because the slight slowing might. be easily overbalanced by an increase in blood viscosity or in peripheral resistance. We can find no circumstance which indicates that there was any significant change in the energy utilized in maintaining blood flow during the periods of decrease in oxygen consumption in our patients.

The respiratory rate changed so little as to be of no significance.

Psychic reactions may be a factor in oxygen consumption and are very hard to evaluate. Most of our patients showed the irritability so often seen in pernicious anemia but none had definite psychoses and all cooperated very satisfactorily. Patients 3 and 4 received luminal in moderate doses without any change in the type of response. Longer control periods would have been desirable in two patients (especially Case 6 ) because excitement occasioned by the test is likely to increase the oxygen consumption at first. This factor, however, is not as important in pernicious anemia as in Graves' disease. In four of the patients the control periods were sufficiently long (8 to 12 days).

From the foregoing considerations we must conclude that the orderly and gradual decrease in oxygen consumption which of ten occurs at the beginning of an induced remission in pernicious anemia is not due to changes in the body temperature, pulse rate, respiratory rate or psychic state. The change in oxygen consumption in our cases is the reverse of what would be expected if the generally accepted explanation for the increase in oxygen consumption in pernicious anemia be correct. 
Rapid cell growth and an excessive oxygen utilization by young cells have been almost universally accepted as factors contributing to the increased oxygen requirement in pernicious anemia, erythremia, leukemia and lymphoma. Obviously new cells are being formed rapidly in the last three diseases but there is some difference of opinion about the rapidity of cell formation during induced remissions in pernicious anemia.

It is to be recalled that Alt (7) reported observations which he interpreted as showing an increase in oxygen consumption during reticulocyte crises in pernicious anemia. This increase was attributed to overactivity of the blood forming tissues. Alt also found a lowered oxygen metabolism during the regenerative period when the blood forming organs must still have been rather active.

The oxygen consumption of adult erythrocytes is practically nihil, but Harrop (13) found that blood containing numerous reticulocytes consumed a measurable amount of oxygen. Accordingly the circulating blood might use more oxygen during a reticulocyte crisis than at other times, but this effect, if present, is usually completely overshadowed by some more potent influence.

That rapid cell growth in the adult organism will result in an increase in the total oxygen requirement is an assumption which seems to have gone unchallenged, but we should remind ourselves that it has not been proved, and our observations as well as those of some other investigators (14) indicate that it may be erroneous.

Rapid cell formation and rapid cell destruction coexist very commonly in diseases of the blood forming organs, and it has been very difficult to determine which of these processes is responsible for the changes in oxygen consumption which exist. Isaacs (15) suggested a relationship between the increased destruction of nuclear material and the increased oxygen consumption in erythremia, leukemia and pernicious anemia. In the first two at least and probably in all of these diseases there is rapid cell formation as well as rapid cell destruction. In a patient not reported in this series we found basal metabolic rates of 22.4 per cent and 23.2 per cent above normal during a reticulocyte crisis. At the time of these determinations 56 per cent of the erythrocytes were reticulated, and nucleated blood cells numbered 53,800 per $\mathrm{cmm}$., of which 26,900 per $\mathrm{cmm}$. ( 50 per cent) were nucleated 
erythrocytes and 19.100 were neutrophiles. Unfortunately, we know nothing of the oxygen consumption either just before or just after this crisis, nor do we know anything about the uric acid metabolism or nitrogen balance. Among the patients whom we studied systematically one (Case 4) showed a slight rise in the basal metabolic rate during the beginning of the reticulocyte crisis, but the rate fell rapidly and was falling during the peak of the crisis. Even if all patients showed an increase in the oxygen consumption during the reticulocyte crisis we would have no proof that such an increase was the result of cell formation rather than nuclear destruction. Riddle (16) showed that the endogenous uric acid metabolism is increased in beginning remissions even before the reticulocyte crisis appears, and that the uric acid content of both the blood and urine falls before the reticulocyte crisis disappears. During the regenerative period which follows the first part of the reticulocyte crisis, we have, in pernicious anemia, a blood dyscrasia in which there is at least normally rapid cell formation without a correspondingly rapid cell destruction unless extruded nuclei are being destroyed.

Rubner (17) and Hoobler (18) separately showed that amino acids which enter into the formation of body proteins exert no specific dynamic action. When protein is stored there is also a saving of the oxygen which would have been required to metabolize it. It would seem that, during a relapse, patients with pernicious anemia are in partial protein starvation in spite of an adequate protein intake, and that by specific therapy they are suddenly rendered able to use and store nitrogen in a normal fashion. All investigators seem to agree that treatment with liver extract results in nitrogen retention regardless of any change in the protein intake. Under such circumstances the conservation of useable amino acids would seem to involve less waste (specific dynamic action) and probably less use of oxygen than would the catabolism of those amino acids.

The changes in nitrogen balance are, in some instances, not great enough to account for the changes in oxygen consumption. That is, the oxygen involved in the estimated specific dynamic action together with oxygen which would have been required to metabolize the stored protein will not always be equivalent to the lowering which occurs in the total oxygen requirement. In this connection, we should re- 
member the tendency of the body to retain some portions of broken down cells which can be used again (e.g., iron). It may be that the body is using certain protein fractions over and over again in an effort to perfect some type of protoplasm which is essential to normal hematopoiesis (stroma of erythrocytes?). The human organism can utilize protein derived from the body of any other animal and we are not aware of any proof that it can not re-utilize its own broken down protein. If re-utilization of protein takes place an added quantity of oxygen might be involved in the process.

Almost the converse of the above state of affairs can be demonstrated in some patients with leukemia who are given roentgen ray treatment. Results of such observations will be reported in a subsequent paper.

Several observations, some of which have been described by other investigators and which are more or less incidental to this study, will be enumerated.

1. As the blood count increased there was a tendency toward a decrease in both the volume index and the color index.

2. Serum bilirubin fell to a normal level promptly after liver therapy was begun.

3. The appetite increased soon after the reticulocyte crisis.

4. In four patients the respiratory quotient increased significantly under treatment whereas in the other two there was a decrease.

5. The urine volume averaged slightly less than the liquid intake during the control period (Table 2). During the first 6 days of liver extract therapy the urine volume decreased still more but during the remainder of the period there was a distinct diuresis. No attempt was made to measure the imperceptible water loss.

6. The uric acid excretion (Table 2) increased at the beginning of the reticulocyte crisis and continued high for several days.

7. The urea excretion (Table 2) decreased during the reticulocyte crisis but returned to its previous level early in the period of regeneration.

8. In Case 6 the nitrogen content of the stool was ten times as much for the first 6-day period as for the last period of 6 days. Much of this variation was no doubt due to diarrhea. 


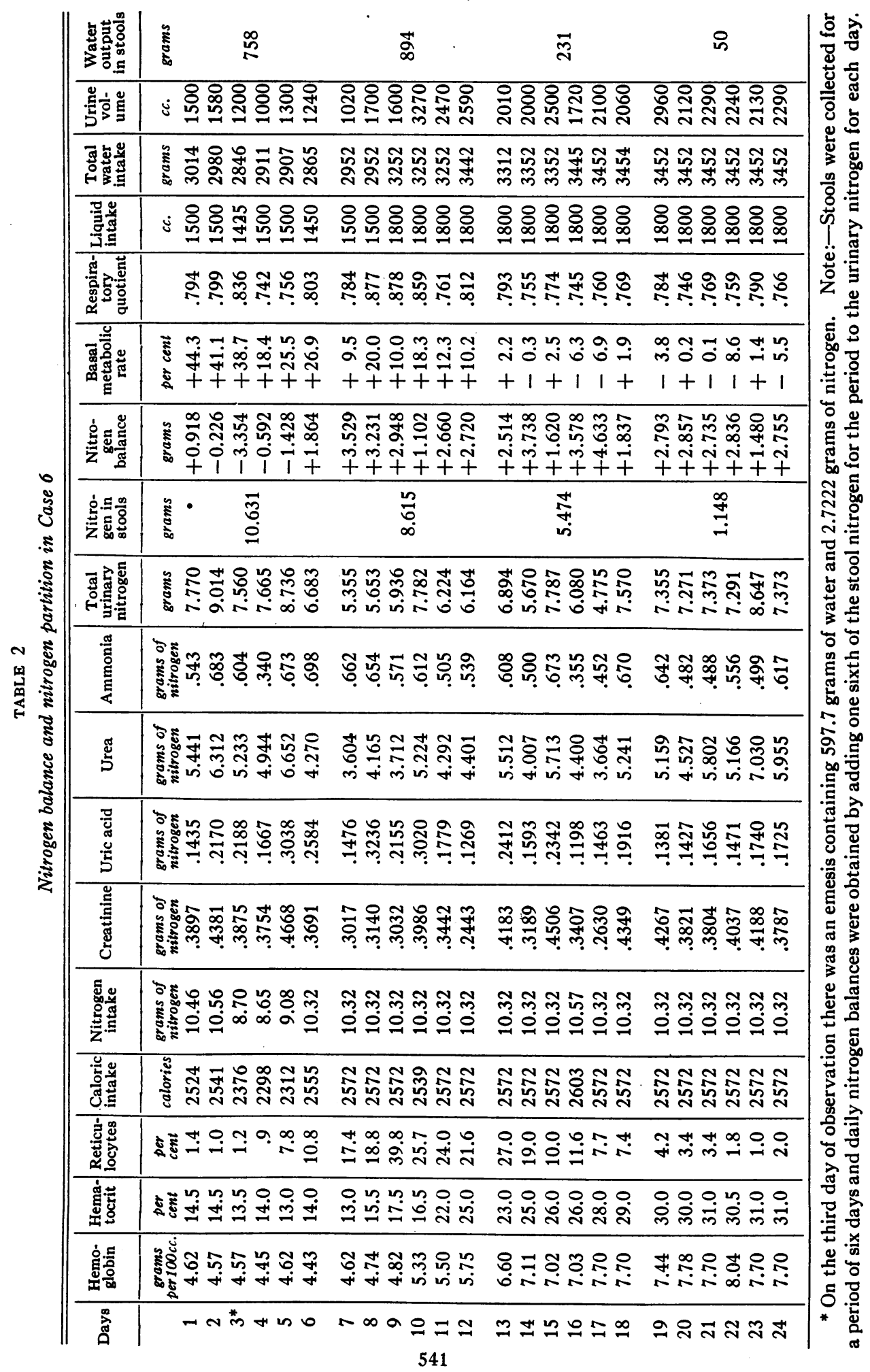


SUMMARY

A blood dyscrasia (pernicious anemia) has been studied during relapses and remissions. Early in induced remissions the influences which cause a lowering of the oxygen requirement are usually potent enough to counteract the effect of two factors which might in themselves tend to increase the oxygen requirement during this period. These two factors are, first, the increased oxygen requirement of circulating reticulocytes, and, second, the increased oxygen required to maintain the high level of endogenous uric acid metabolism which exists. During an active relapse blood cells are being destroyed more rapidly than they are formed, and there is a negative nitrogen balance with an increased oxygen consumption. During induced remissions blood cells are being formed much more rapidly than they are being destroyed and there is nitrogen retention with a decreasing oxygen consumption. We wish to suggest the following as a working hypothesis: There is a direct causal relationship between the increase in nitrogen catabolism and the increased oxygen consumption, and a similar relationship of cause and effect between nitrogen storage and decrease in oxygen requirement.

\section{BIBLIOGRAPHY}

1. Meyer, A. L. and DuBois, E. F., Arch. Int. Med., 1916, xvii, 965. Clinical Calorimetry. XV. The Basal Metabolism in Pernicious Anemia.

2. Tompkins, E. H., Brittingham, H. H. and Drinker, C. K., Arch. Int. Med., 1919, xxiii, 441. The Basal Metabolism in Anemia with Especial Reference to the Effect of Blood Transfusion on the Metabolism in Pernicious Anemia.

3. Grafe, E., Ergebn. d. Physiol., 1923, xxi, Pt. II, 1. Die pathologische Physiologie des Gesamtstoff- und Kraftwechsels bei der Ernährung des Menschen.

4. Boothby, W. M. and Sandiford, I., J. Biol. Chem., 1922, liv, 783. Summary of the Basal Metabolism Data on 8614 Subjects with Especial Reference to the Normal Standards for the Estimation of the Basal Metabolic Rate.

5. Becker, G., Acta med. Scandinav., 1925-1926, lxiii, 478. Studien über den Stoffwechsel bei perniziöser Anämie.

6. Richards, D. W., Jr. and Strauss, M. L., J. Clin. Invest., 1928, v, 161. Circulatory Adjustment in Anemia.

7. Alt, H. L., Arch. Int. Med., 1929, xliii, 488. The Metabolism in Pernicious Anemia. 
8. Grassheim, K., Klin. Wchnschr., 1928, vii, 1424. Untersuchungen über den Stoffwechsel bei der Perniziösen Anämie unter besonderer Berücksichtigung der Leberdiät.

9. Gibson, R. B. and Howard, C. P., Arch. Int. Med., 1923, xxxii, 1. Metabolic Studies in Pernicious Anemia.

10. Fenlon, R. L., J. Iowa State Med. Soc., 1921, xi, 50. A Diet for Pernicious Anemia.

11. Meulengracht, E., Iverson, P. and Nakazawa, F., Arch. Int. Med., 1928, xlii, 425. Pernicious Anemia. Anemia and Reduction in Excretion of Water.

12. Rohner, F. J., J. Iowa State Med. Soc., 1922, xii, 216. Pernicious Anemia: A Study of One Hundred and Twenty-seven Cases.

13. Harrop, G. A., Jr., Arch. Int. Med., 1919, xxiii, 745. The Oxygen Consumption of Human Erythrocytes.

14. Lee, M. O. and Gagnon, J., Proc. Soc. Exp. Biol. and Med., 1930, xxviii, 16. Effect of Growth Promoting Extracts of the Anterior Pituitary on Basal Gaseous Metabolism in Rats.

15. Isaacs, R., Arch. Int. Med., 1923, xxxi, 289. Pathologic Physiology of Polycythemia Vera.

16. Riddle, M. C., J. Clin. Invest., 1929, viii, 69. The Endogenous Uric Acid Metabolism in Pernicious Anemia.

17. Rubner, M., Die Gesetze des Energieverbrauchs bei der Ernährung. Leipzig, Deuticke, 1902, p. 256.

18. Hoobler, B. R., Am. J. Dis. Child., 1915, x, 153. The Protein Need of Infants.

19. Newcomer, H. S., J. Biol. Chem., 1923, lv, 569. A New Optical Instrument for the Determination of Hemoglobin.

20. Van Allen, C. M., J. Lab. and Clin. Med., 1925, x, 1027. An Hematocrit Method. 